\title{
On the Helical Structure of Guanosine $5^{\prime}$-Monophosphate Formed at pH 5: Is It Left- or Right-Handed?
}

\author{
Gang Wu, ${ }^{1}$ Irene C. M. Kwan, ${ }^{1}$ Zhimin Yan, ${ }^{2}$ Yining Huang, ${ }^{2}$ and Eric $\mathrm{Ye}^{3}$ \\ ${ }^{1}$ Department of Chemistry, Queen's University, 90 Bader Lane, Kingston, ON, Canada K7L 3N6 \\ ${ }^{2}$ Department of Chemistry, Western University, London, ON, Canada N6A 5B7 \\ ${ }^{3}$ Department of Chemistry, University of Ottawa, Ottawa, ON, Canada K1N 6N5 \\ Correspondence should be addressed to Gang Wu; wugang@queensu.ca
}

Received 24 July 2017; Accepted 11 October 2017; Published 2 November 2017

Academic Editor: Gary Parkinson

Copyright (c) 2017 Gang Wu et al. This is an open access article distributed under the Creative Commons Attribution License, which permits unrestricted use, distribution, and reproduction in any medium, provided the original work is properly cited.

Early X-ray fiber diffraction studies have established that the spontaneous gel formation of guanosine $5^{\prime}$-monophosphate ( $5^{\prime}$-GMP) under slightly acidic conditions (e.g., pH 5) results from self-assembly of $5^{\prime}$-GMP into a helical structure in which hydrogen-bonded guanine bases form a continuous helix with 15 nucleotides per 4 turns. For more than five decades, the sense of this helix is believed to be left-handed. Using multinuclear solid-state NMR and IR spectroscopic methods, we have finally determined the long-missing structural details of this helix. First, we found that this $5^{\prime}$-GMP helix is right-handed containing exclusive C $3^{\prime}$-endo sugar puckers. Second, we showed that the central channel of this helix is free of $\mathrm{Na}^{+}$ions, which is in sharp contrast to the helix formed by $5^{\prime}$-GMP at $\mathrm{pH} 8$ where the central channel is filled with $\mathrm{Na}^{+}$ions.

\section{Introduction}

Gel formation of guanosine $5^{\prime}$-monophosphate $\left(5^{\prime}\right.$-GMP) under slightly acidic conditions (e.g., $\mathrm{pH}$ 5) was first discovered by Bang in 1910 [1]. However, it was not until 50 years later that the structural basis of such $5^{\prime}$-GMP gel was examined. In 1962, Gellert et al. [2] used X-ray fiber diffraction data to show that different GMP isomers form different helical structures. For $3^{\prime}$-GMP gel, the helical structure is formed by successive stacking of planar hydrogen-bonded guanine tetramers now known as the G-quartets on top of each other. For $5^{\prime}$-GMP gel formed at $\mathrm{pH} 5$, in contrast, the planar (disc-like) G-quartet is broken at one side forming a lock-washer-like structure which is further hydrogen bonded into a continuous helix; see Figure 1. In 1975, Sasisekharan et al. [3] further investigated the helical structure formed by $5^{\prime}$-GMP at $\mathrm{pH} 5$ (i.e., $5^{\prime}$-GMP gel) and reported atomic coordinates for a left-handed 15/4 helix model. However, these authors also noted in the paper that " $[b]$ ecause the helix is not constrained by a continuous covalently bonded backbone, both right-and left-handed helices of the 15/4 model can be constructed. Although stereochemically quite different, they are both acceptable. ...For arbitrary reasons, we have selected for detailed examination a left-handed helix...." Therefore, it appears that, on the basis of the original fiber X-ray diffraction data alone, there is no particular reason to favor a left-handed helix over a right-handed one. However, this arbitrary choice of the helical structure has been overlooked in the literature so that, even in classic treatises of nucleic acid structures such as that by Saenger [4], this helix is described as left-handed. It is also clear from the study of Sasisekharan et al. [3] that whether the acidic 5'-GMP helix is left- or righthanded depends critically on the sugar pucker conformation. That is, a $\mathrm{C}^{\prime}$-endo sugar pucker would favor a left-handed helix but a $\mathrm{C}^{\prime}$-endo conformation would result in a righthanded helix. However, because $5^{\prime}$-GMP gels are difficult to study with common spectroscopic techniques, the question regarding its exact helical structure has never been fully addressed.

In 2009, we used solution NMR techniques to obtain structural details of the helix formed by $5^{\prime}$-GMP at $\mathrm{pH} 8$ [5]. As shown in Figure 1, the physical appearance of the $5^{\prime}$-GMP solution depends critically on the $\mathrm{pH}$. At $\mathrm{pH} 8$, the $5^{\prime}$-GMP solution appears as a normal liquid, whereas, 


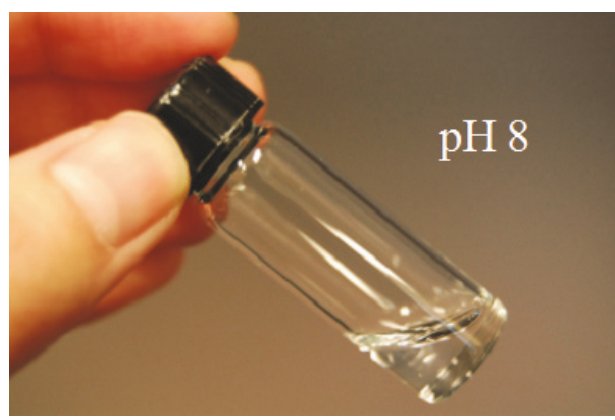

(a)

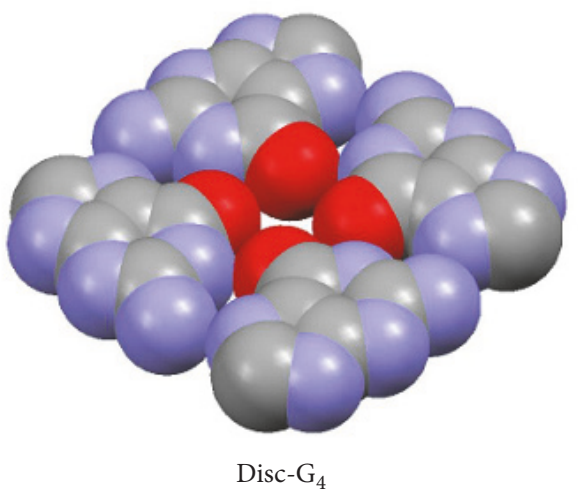

(c)

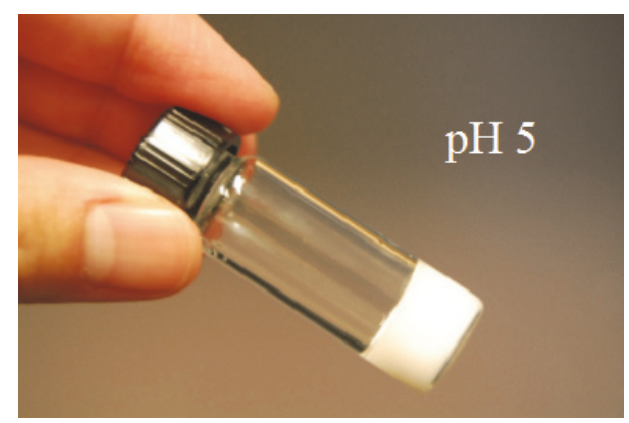

(b)

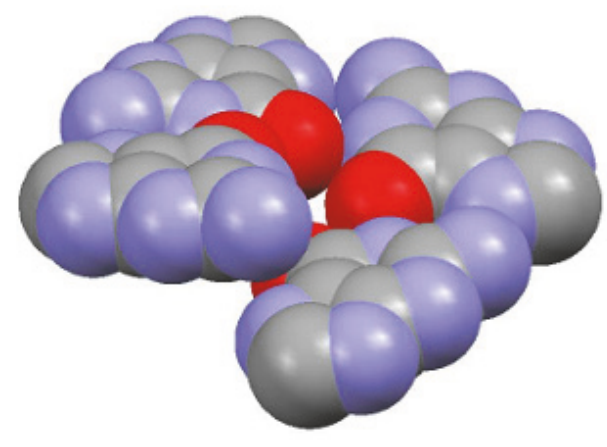

Lock-washer-G $\mathrm{G}_{4}$

(d)

FIGURE 1: Contrasting physical appearance of $1.0 \mathrm{M} \mathrm{Na}_{2}\left(5^{\prime}\right.$-GMP) aqueous solution at pH 8 (a) and pH 5 (b) and the two structural motifs responsible for the $5^{\prime}$-GMP self-assembly: (c) planar G-quartet (disc- $\mathrm{G}_{4}$ ) and (d) open-ended G-quartet (lock-washer- $\left.\mathrm{G}_{4}\right)$.

at $\mathrm{pH}$, it becomes a gel. The key findings of our earlier study of the $5^{\prime}$-GMP helix formed at $\mathrm{pH} 8$ are as follows. First, the central structural motif of the helix is the disclike $\mathrm{G}_{4}$. Second, the $5^{\prime}$-GMP molecules take alternating $\mathrm{C}^{\prime}{ }^{\prime}$ endo and $\mathrm{C}^{\prime}$-endo sugar pucker conformation along the helical strand. Third, the helix is right-handed. Fourth, the central channel of the helix is filled with $\mathrm{Na}^{+}$ions each being sandwiched between two disc-like $\mathrm{G}_{4}$ s. In contrast, as Sasisekharan et al. [3] proposed, the central structural motif of the helix formed by $5^{\prime}$-GMP at $\mathrm{pH} 5$ is a lock-washerlike $\mathrm{G}_{4}$ structure, as illustrated in Figure 1. However, other details about this helix are not known. Since $5^{\prime}$-GMP forms gel at $\mathrm{pH} 5$, conventional solution NMR techniques are not applicable. In this work, we applied solid-state NMR and IR methods to obtain structural details about the helical structure formed by $5^{\prime}$-GMP at $\mathrm{pH} 5$ ( $5^{\prime}$-GMP gels). In particular, we set out to address key questions concerning sugar pucker conformation, phosphate-phosphate interaction, phosphatebase interaction, and metal ion binding environment around the helical structure.

\section{Experimental Sections}

Hydrated disodium salt of guanosine $5^{\prime}$-monophosphate (purity > 99\%) was obtained from Sigma-Aldrich (Ontario, Canada). The $5^{\prime}$-GMP gel sample was prepared by acidifying 1.0 $\mathrm{M} \mathrm{Na}_{2}\left(5^{\prime}-\mathrm{GMP}\right)$ aqueous solution to $\mathrm{pH} 5$ with acetic acid. Before the solid-state NMR experiments, the gel was gently dried with a stream of $\mathrm{N}_{2}$. The $1 \mathrm{D}{ }^{1} \mathrm{H}$ MAS and $2 \mathrm{D}{ }^{1} \mathrm{H}$ double quantum (DQ) NMR experiments were performed at 21.1 T with a Bruker $1.3 \mathrm{~mm}$ HX probe with a sample spinning frequency of $62.5 \mathrm{kHz}$. The back-to-back (BABA) recoupling sequence [7] was used for the ${ }^{1} \mathrm{H}$ DQ experiments with the excitation time being set to one rotor period. The recycle time employed was $8 \mathrm{~s}$. The $2 \mathrm{D}{ }^{1} \mathrm{H} \rightarrow{ }^{31} \mathrm{P}$ HETCOR experiments were performed at $21.1 \mathrm{~T}$ with a Bruker 2.4-mm MAS probe. The sample spinning frequency was $33 \mathrm{kHz}$. Contact times from 0.5 to $2.0 \mathrm{~ms}$ were employed. Solid-state ${ }^{13} \mathrm{C} \mathrm{CP} / \mathrm{MAS}$ NMR experiments were performed at 14.1 and $21.1 \mathrm{~T}$. All ${ }^{13} \mathrm{C}$ chemical shifts were referenced to that of TMS by setting the ${ }^{13} \mathrm{C}$ signal of a solid sample of tetrakis (trimethylsilyl) silane (TKS) to $3.50 \mathrm{ppm}$. Solid-state ${ }^{31} \mathrm{P}$ NMR experiments were performed on a Bruker Avance-600 spectrometer operating at $242.96 \mathrm{MHz}$ for ${ }^{31} \mathrm{P}$. All ${ }^{31} \mathrm{P}$ chemical shifts were referenced to $85 \% \mathrm{H}_{3} \mathrm{PO}_{4}(\mathrm{aq})$. Solid-state ${ }^{23} \mathrm{Na} \mathrm{NMR}$ experiments were performed on a Bruker Avance-500 spectrometer operating at $132.72 \mathrm{MHz}$ for ${ }^{23} \mathrm{Na}$ nuclei with the following parameters: sample spinning, $10 \mathrm{kHz} ;{ }^{1} \mathrm{H}$ decoupling, $65 \mathrm{kHz}$; recycle time, $10 \mathrm{~s}$; 64 transients. All ${ }^{23} \mathrm{Na}$ chemical shifts were referenced to $\mathrm{NaCl}(\mathrm{aq})$ at $\delta=0.0 \mathrm{ppm}$ by setting the ${ }^{23} \mathrm{Na}$ signal of $\mathrm{NaCl}(\mathrm{s})$ to $7.21 \mathrm{ppm} .{ }^{23} \mathrm{Na}\left\{{ }^{31} \mathrm{P}\right\}$ REDOR experiments using the original version of the pulse sequence [8] were performed on a Varian/Chemagnetics Infinity-Plus $400 \mathrm{WB}$ 
spectrometer operating at a magnetic field strength of $9.4 \mathrm{~T}$. The ${ }^{31} \mathrm{P}$ and ${ }^{23} \mathrm{Na}$ resonance frequencies at this field strength are 161.72 and $105.67 \mathrm{MHz}$, respectively. All MAS spectra were acquired using a Varian/Chemagnetics T3 4-mm tripletuned MAS probe. Typical RF power levels corresponded to $180^{\circ}$ pulse lengths of 7.0 and $7.8 \mu$ s for ${ }^{23} \mathrm{Na}$ and ${ }^{31} \mathrm{P}$ nuclei, respectively. A total of 512 transients were accumulated for each REDOR measurement. The sample spinning rate was kept constant at $10000 \pm 2 \mathrm{~Hz}$. The recycle delay was $0.2 \mathrm{~s}$.

\section{Results and Discussion}

To assess the basic self-assembled structure of $5^{\prime}$-GMP gel formed at $\mathrm{pH} 5$, we first obtained its ${ }^{1} \mathrm{H}$ solid-state NMR spectra under very fast MAS conditions at an ultrahigh magnetic field, $21.1 \mathrm{~T}\left(900 \mathrm{MHz}\right.$ for $\left.{ }^{1} \mathrm{H}\right)$. For comparison, we also reported the corresponding ${ }^{1} \mathrm{H}$ NMR spectra for crystalline $\mathrm{Na}_{2}\left(5^{\prime}\right.$-GMP) $\cdot 7 \mathrm{H}_{2} \mathrm{O}$ (orthorhombic). As seen in Figure 2, for the acidic $5^{\prime}$-GMP gel sample, the $\mathrm{N}_{1} \mathrm{H}$ and $\mathrm{N}_{2} \mathrm{H}^{\mathrm{A}}$ signals appear at about $10.6 \mathrm{ppm}$, suggesting that both protons are involved in strong hydrogen bonding. The DQ signals connecting $\mathrm{N}_{2} \mathrm{H}^{\mathrm{A}}$ and $\mathrm{H} 8$ provide the most direct evidence for $\mathrm{G}_{4}$ formation, although this feature alone cannot reliably distinguish between the planar disk- $\mathrm{G}_{4}$ and lock-washer- $\mathrm{G}_{4}$ motifs (vide infra). Interestingly, two $\mathrm{N}_{1} \mathrm{H}$ signals are seen for $\mathrm{Na}_{2}\left(5^{\prime}\right.$-GMP) $\cdot 7 \mathrm{H}_{2} \mathrm{O}$ (orthorhombic). This observation is consistent with the crystal structure of the compound where there are two distinct $5^{\prime}$-GMP molecules in the asymmetric unit [9]. This doubling of the signals is more evident in the ${ }^{13} \mathrm{C}$ CP/MAS spectrum of $\mathrm{Na}_{2}\left(5^{\prime}-\mathrm{GMP}\right) \cdot 7 \mathrm{H}_{2} \mathrm{O}$ (orthorhombic) (see Figure S1 in the Supporting Information, available online at https://doi.org/10.1155/2017/6798759). Furthermore, for $\mathrm{Na}_{2}\left(5^{\prime}\right.$-GMP). $7 \mathrm{H}_{2} \mathrm{O}$ (orthorhombic), the $\mathrm{N}_{1} \mathrm{H}$ signals appear at about $13.5 \mathrm{ppm}$, whereas the corresponding $\mathrm{N}_{2} \mathrm{H}$ signals are between 4 and $6 \mathrm{ppm}$. These observed ${ }^{1} \mathrm{H}$ chemical shifts are in agreement with the crystal structure of $\mathrm{Na}_{2}\left(5^{\prime}\right.$-GMP) $7 \mathrm{H}_{2} \mathrm{O}$ (orthorhombic) which shows that $\mathrm{N}_{1} \mathrm{H}$ forms a strong hydrogen bond with ${ }^{-} \mathrm{O}-\mathrm{P}$ (the two $\mathrm{N} \cdots \mathrm{O}$ distances are 2.76 and $2.79 \AA$ ) and the $\mathrm{N}_{2} \mathrm{H}$ groups are only weakly hydrogen bonded to water molecules (two $\mathrm{N} \cdots \mathrm{O}_{\mathrm{W}}$ distances are 2.91 and $2.95 \AA$ ) [9]. It is interesting to note that both acidic $5^{\prime}$-GMP gel and $\mathrm{Na}_{2}\left(5^{\prime}\right.$-GMP). $7 \mathrm{H}_{2} \mathrm{O}$ exhibit DQ signals between $\mathrm{H} 8$ and $\mathrm{H}^{\prime}, 5^{\prime \prime}$, consistent with the guanine base being in the anti-conformation. Now, while the ${ }^{1} \mathrm{H}$ solidstate NMR data confirm G4 formation for the acidic $5^{\prime}$-GMP gel, they provide no information about the sense of the helix.

As mentioned earlier, on the basis of modeling performed by Sasisekharan et al. [3], whether the acidic $5^{\prime}$-GMP helix is left- or right-handed depends critically on the sugar pucker conformation. To answer this question, we utilized a wellestablished approach in using ${ }^{13} \mathrm{C}$ chemical shifts of the sugar carbons as a means of determining the sugar pucker conformation. In particular, Harbison and coworkers [10, 11] showed that, for RNA nucleosides and nucleotides, one can combine the ${ }^{13} \mathrm{C}$ chemical shifts observed for the ribose moiety into the following two canonical coordinates:

$$
\text { can1 }=0.179 \delta\left(\mathrm{Cl}^{\prime}\right)-0.225 \delta\left(\mathrm{C}^{\prime}\right)-0.0585 \delta\left(\mathrm{C}^{\prime}\right),
$$

$$
\begin{aligned}
\operatorname{can} 2= & -0.0605\left[\delta\left(\mathrm{C} 2^{\prime}\right)+\delta\left(\mathrm{C} 3^{\prime}\right)\right]-0.0556 \delta\left(\mathrm{C} 4^{\prime}\right) \\
& -0.0524 \delta\left(\mathrm{C} 5^{\prime}\right) .
\end{aligned}
$$

Then any data point appearing in the can1-can2 plot can be used to determine the sugar pucker conformation (can1 $>-6.77$ for $\mathrm{C} 3^{\prime}$-endo and can $1<-6.77$ for $\mathrm{C} 2{ }^{\prime}$-endo) as well as the exocyclic $\gamma$-torsion angle (can $2<-16.82$ for $g t$ and can2 > -16.82 for $g g$ ). Later, Ohlenschläger et al. [12] applied this approach to analyze a total of 429 known RNA structures and showed that the reliability of this approach for purine nucleotides is 93-94\% (see Figure S2 in the Supporting Information).

Figure 3(a) shows the solid-state ${ }^{13} \mathrm{C} C \mathrm{CP} / \mathrm{MAS}$ NMR spectrum of acidic $5^{\prime}$-GMP gel where the observed ${ }^{13} \mathrm{C}$ chemical shifts for sugar carbons $\mathrm{Cl}^{\prime}, \mathrm{C2}^{\prime}, \mathrm{C}^{\prime}, \mathrm{C}^{\prime}$, and $\mathrm{C}^{\prime}$ are $87.9,76.3,69.3,82.2$, and $62.8 \mathrm{ppm}$, respectively. This assignment was further confirmed by DFT calculations on the ${ }^{13} \mathrm{C}$ chemical shifts for a model $5^{\prime}$-GMP molecule. These values yield can $1=-6.43$ and $\operatorname{can} 2=-16.67$ for the acidic $5^{\prime}$-GMP gel. Now the fact that canl $>-6.77$ and can $2>-16.82$ for the acidic $5^{\prime}$-GMP gel strongly suggests that the sugar pucker conformation is exclusively $\mathrm{C} 3^{\prime}$-endo with the exocyclic $\gamma$-torsion angle being in the $g g$ conformation [10-12]; see Figure S2 in the Supporting Information. These canonical coordinates are quite different from those for $\mathrm{Na}_{2}\left(5^{\prime}-\mathrm{GMP}\right) \cdot 7 \mathrm{H}_{2} \mathrm{O}$ (orthorhombic) and $5^{\prime}$-GMP selfassembly formed at pH 8; also see Figure S2 in the Supporting Information. This new information about the $\mathrm{C}^{\prime}$-endo sugar pucker conformation means that the continuous helix of the acidic $5^{\prime}$-GMP gel is right-handed. To further confirm the $\mathrm{C}^{\prime}$-endo sugar pucker conformation determined above, we recorded FTIR spectra for three $5^{\prime}$-GMP samples. Some time ago, Tajmir-Riahi [13] showed that the P-O-5'-ribose stretch frequency can be used as the signature for the sugar pucker conformation for guanylic acid and its salts: $800 \mathrm{~cm}^{-1}$ for $\mathrm{C}^{\prime}$ endo and $820 \mathrm{~cm}^{-1}$ for $\mathrm{C}^{\prime}$-endo. As seen from Figure 3(b), the acidic $5^{\prime}$-GMP gel sample indeed displays a peak at $800 \mathrm{~cm}^{-1}$, confirming the aforementioned $\mathrm{C} 3^{\prime}$-endo sugar pucker conformation. In comparison, the FTIR spectrum of the $5^{\prime}$-GMP self-assembly formed at $\mathrm{pH} 8$ exhibits both 800 and $820 \mathrm{~cm}^{-1}$ peaks of equal intensity. This is in agreement with the earlier observation that the helical structure of $5^{\prime}$-GMP formed at $\mathrm{pH} 8$ consists of alternating $\mathrm{C}^{\prime}$-endo and $\mathrm{C} 2^{\prime}$-endo sugar pucker conformation [5]. For $\mathrm{Na}_{2}\left(5^{\prime}-\right.$ GMP) $\cdot 7 \mathrm{H}_{2} \mathrm{O}$ (orthorhombic), the observation of a peak at $820 \mathrm{~cm}^{-1}$ is in agreement with its crystal structure where the ribose is in the $\mathrm{C} 2^{\prime}$-endo conformation [9]. Therefore, the FTIR data shown in Figure 3(b) are fully consistent with the results on sugar pucker conformation obtained from the ${ }^{13} \mathrm{C}$ chemical shift analysis. Now, combining the $\mathrm{C} 3^{\prime}$-endo sugar pucker conformation with the helical parameters reported by Sasisekharan et al. [3], we can readily build a right-handed 15/4 helix model; see Figure S3 and Table S1 in the Supporting Information for atomic coordinates.

Since metal ion binding is an integral part of Gquadruplex formation [14-18], we further investigated how 


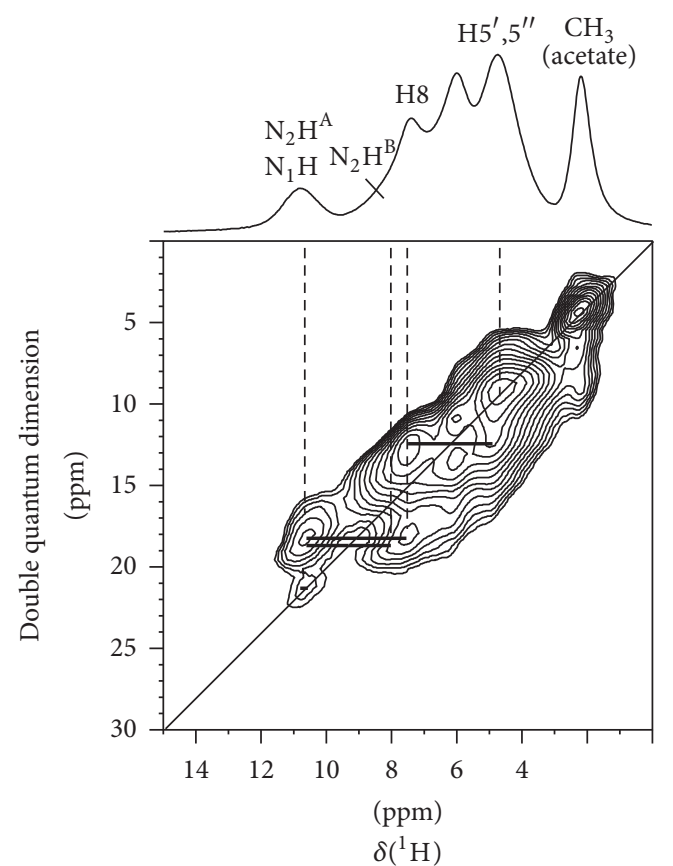

(a)

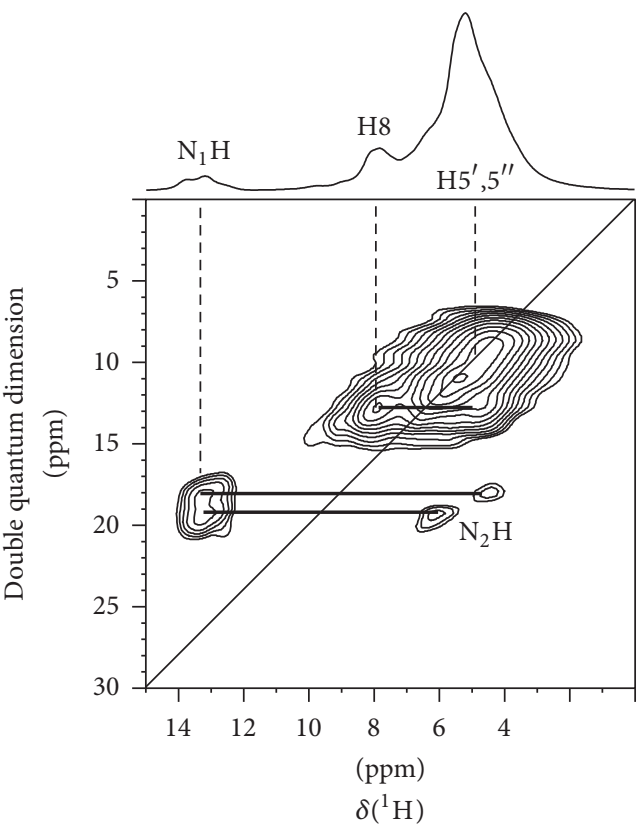

(b)

Figure 2: 2D ${ }^{1} \mathrm{H}$ DQ NMR spectra of (a) dried $5^{\prime}$-GMP gel formed at $\mathrm{pH} 5$ and (b) $\mathrm{Na}_{2}\left(5^{\prime}\right.$-GMP) $7 \mathrm{H}_{2} \mathrm{O}$ (orthorhombic). The corresponding $1 \mathrm{D}^{1} \mathrm{H}$ NMR spectra are shown at the top. All ${ }^{1} \mathrm{H}$ NMR spectra were obtained under the MAS condition with a sample spinning frequency of $62.5 \mathrm{kHz}$ at $21.1 \mathrm{~T}$.

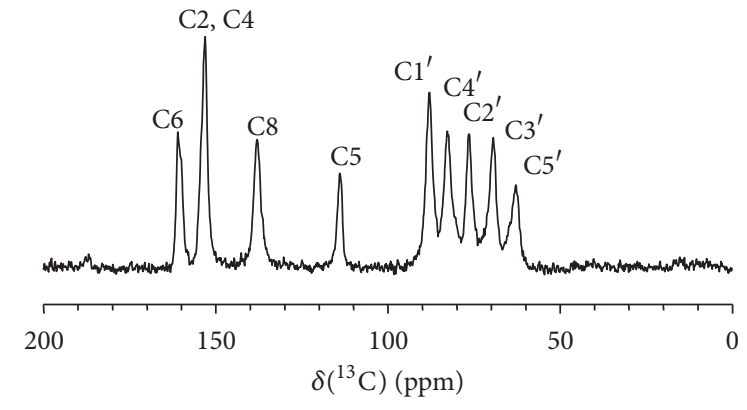

(a)
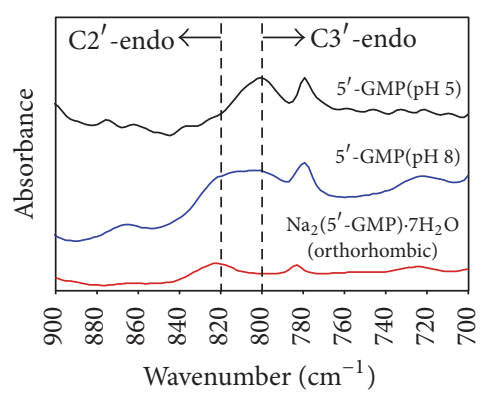

(b)

FIGURE 3: (a) ${ }^{13} \mathrm{C}$ CP/MAS NMR spectrum of dried $5^{\prime}$-GMP gel formed at $\mathrm{pH}$ 5. (b) The signature region of IR spectra revealing sugar pucker conformation for $5^{\prime}$-GMP gel ( $\left.\mathrm{pH} 5\right), 5^{\prime}$-GMP ( $\mathrm{pH} 8$ ), and $\mathrm{Na}_{2}\left(5^{\prime}-\mathrm{GMP}\right) \cdot 7 \mathrm{H}_{2} \mathrm{O}$ (orthorhombic).

$\mathrm{Na}^{+}$ions are bound to the acidic $5^{\prime}$-GMP helical structure. Figure 4 shows the solid-state ${ }^{23} \mathrm{Na}$ NMR spectra obtained for the acidic $5^{\prime}$-GMP gel as well as for a neutral $5^{\prime}$-GMP selfassembly sample for comparison. The two ${ }^{23} \mathrm{Na}$ NMR signals observed for the acidic $5^{\prime}$-GMP gel can be readily assigned: the sharp signal at $7.2 \mathrm{ppm}$ is due to fully hydrated $\mathrm{Na}^{+}$ ions and the signal centered at $-5.0 \mathrm{ppm}$ is from phosphatebound $\mathrm{Na}^{+}$ions. To further confirm the phosphate-bound nature of the signal at $-5.0 \mathrm{ppm}$, we performed ${ }^{23} \mathrm{Na}\left\{{ }^{31} \mathrm{P}\right\}$ rotational-echo double resonance (REDOR) [8] experiments. As shown in Figure 5, the ${ }^{23} \mathrm{Na}\left\{{ }^{31} \mathrm{P}\right\}$ REDOR results obtained for the acidic $5^{\prime}$-GMP gel are quite similar to those for neutral $5^{\prime}$-GMP and for double-stranded calf thymus DNA in the dry state (A-form) [19]. Thus the ${ }^{23} \mathrm{Na}\left\{{ }^{31} \mathrm{P}\right\}$ REDOR results confirmed unambiguously that the ${ }^{23} \mathrm{Na}$ NMR signal at $-5 \mathrm{ppm}$ arises from $\mathrm{Na}^{+}$ions bound to the phosphate group. The most striking feature in the ${ }^{23} \mathrm{Na}$ NMR spectrum of acidic $5^{\prime}$-GMP gel is the absence of any signal at ca. $-18 \mathrm{ppm}$, which is the established spectral signature for $\mathrm{Na}^{+}$ ions residing inside a G-quadruplex channel [20-22]. This observation immediately suggests that there is no $\mathrm{Na}^{+}$ion inside the central channel of the continuous helix formed by $5^{\prime}$-GMP at $\mathrm{pH} 5$ ! This aspect of the helix, though totally unexpected, can be readily understood on the basis of our structural model. As seen from Figure 6, when a disc-like $G_{4}$ is twisted into a lock-washer-like $G_{4}$, the size of the central 


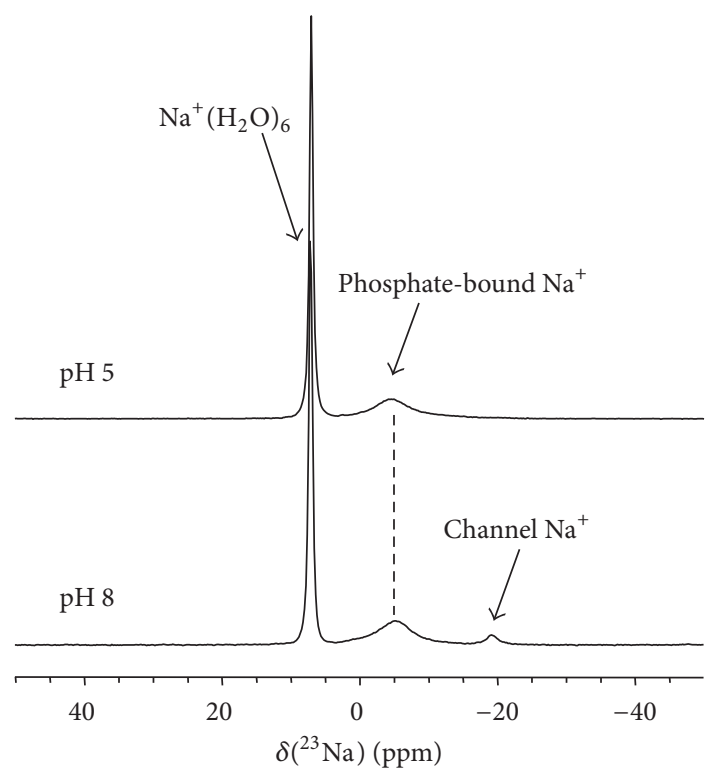

FIGURE $4:{ }^{23} \mathrm{Na}$ MAS NMR spectra of the $5^{\prime}$-GMP samples prepared at $\mathrm{pH} 5$ and $\mathrm{pH} 8$.

cavity surrounded by carbonyl oxygen atoms is significantly reduced. As a result, $\mathrm{Na}^{+}$ions can no longer fit into this cavity. The diameter of the central channel is reduced by nearly $50 \%$ for the acidic $5^{\prime}$-GMP helix compared with that of the neutral $5^{\prime}$-GMP helix, as clearly seen from the top view of the channel shown in Figure 6. This observation is consistent with the fact that $5^{\prime}$-GMP gel formation at $\mathrm{pH} 5$ is not sensitive to the nature of monovalent cations $\left(\mathrm{Na}^{+}, \mathrm{K}^{+}\right.$, or $\left.\mathrm{NH}_{4}^{+}\right)$present in solution. It is also worth noting that the helical structure of acidic $5^{\prime}$-GMP gel is remarkably similar to that found for 8oxoguanosine reported recently by Giorgi et al. [23], despite the very different hydrogen bonding schemes in these two systems. Here we further comment on the role that the central cations play in G-quadruplex systems consisting planar disclike G-quartets. While it is commonly accepted that the central cation is to reduce the repulsion between carbonyl oxygen atoms from G-quartets, it is important to point out that it is primarily the repulsions between carbonyl oxygen atoms from adjacent planar G-quartets, not from within the same G-quartet, which requires further stabilization from a cation. The main evidence for this view is the fact that whereas a cation-free or "empty" G-quartet was observed [24], an "empty" G-octamer has never been reported. Now when the helix is made of lock-washer-like $\mathrm{G}_{4}$, there is no longer any repulsion between carbonyl oxygen atoms along the helical axis, thus making it unnecessary to have a cation inside the central channel.

Now let us turn attention to the phosphate group in the acidic $5^{\prime}$-GMP helix. Since the phosphate group of $5^{\prime}$-GMP has a $\mathrm{p} K_{\mathrm{a} 2}$ of 7.5 , it is doubly charged at $\mathrm{pH} 8$ but only singly charged at pH 5. We discovered in an earlier study [5] that two types of phosphate groups are present in the $5^{\prime}$-GMP helix formed at $\mathrm{pH} 8$ and they are possibly bridged by a $\mathrm{Na}^{+}$ion. For the $5^{\prime}$-GMP helix formed at $\mathrm{pH} 5$, our model suggests that singly charged phosphate groups form a continuous

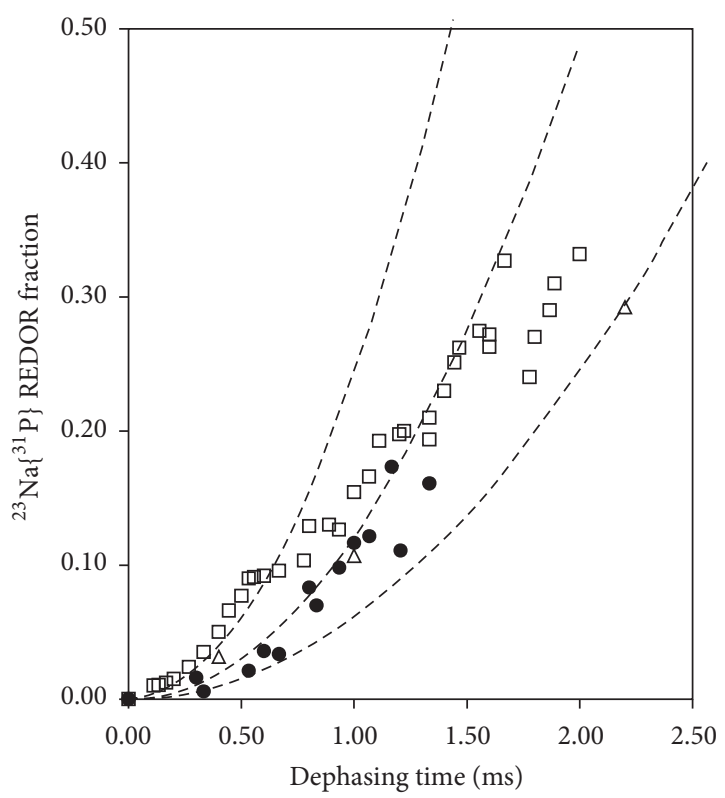

FIGURE 5: ${ }^{23} \mathrm{Na}\left\{{ }^{31} \mathrm{P}\right\}$ REDOR results obtained for ( $\square$ ) $5^{\prime}$-GMP (pH 5), $(\bullet) 5^{\prime}$-GMP (pH 8), and $(\triangle)$ double-stranded calf thymus DNA (Aform). The dash lines are calculated using $\Delta S / S=\left(4 / 3 \pi^{2}\right)\left(N T_{r}\right)^{2} M_{2}$, where $N T_{r}$ is the dephasing time and $M_{2}$ is the second moment of the ${ }^{23} \mathrm{Na}^{31} \mathrm{P}$ dipolar interactions [6]. The three $M_{2}$ values used in the calculations are $1.80,0.90$, and $0.45 \times 10^{6} \mathrm{~s}^{-2}$, corresponding to a Na-P distance between $3.1,3.4$, and $3.7 \AA$, respectively.
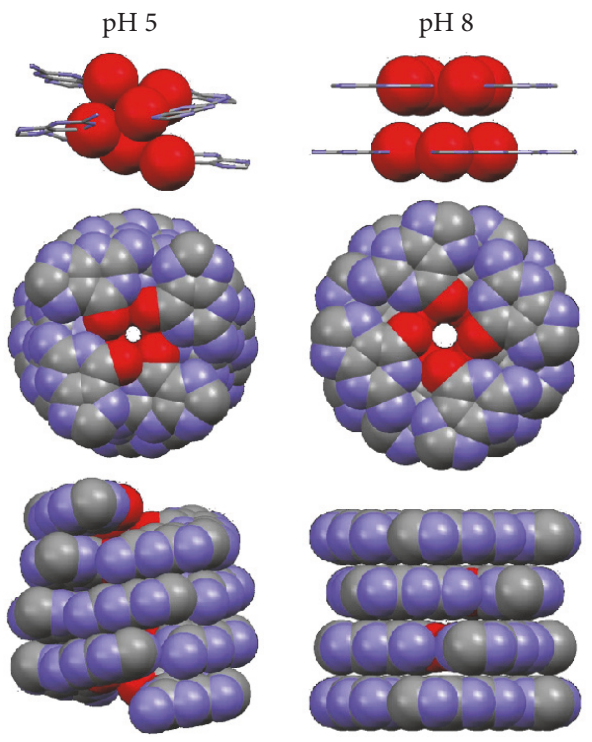

FIGURE 6: Different arrangements of the guanine bases in the helical structures of 5 -GMP self-assembly formed under acidic ( $\mathrm{pH} 5$ ) and neutral ( $\mathrm{pH} 8)$ conditions. Both helices are right-handed.

hydrogen-bonded chain along the helical "strand" (i.e., $\cdots$ HO- $\mathrm{P}_{i}-\mathrm{O}^{-} \cdots$ HO- $\left.\mathrm{P}_{i+1}-\mathrm{O}^{-} \cdots\right)$. This type of hydrogen bond chains are commonly observed in the crystal structures of ammonium hydrogen alkylphosphates [25]. Because of this strong hydrogen bonding interaction, the P...P distance is significantly shorter in the acidic $5^{\prime}$-GMP helix, $5.2 \AA$, than in the neutral $5^{\prime}$-GMP helix (6.7 and 7.2 $\AA$ ) [5]. The solid-state 


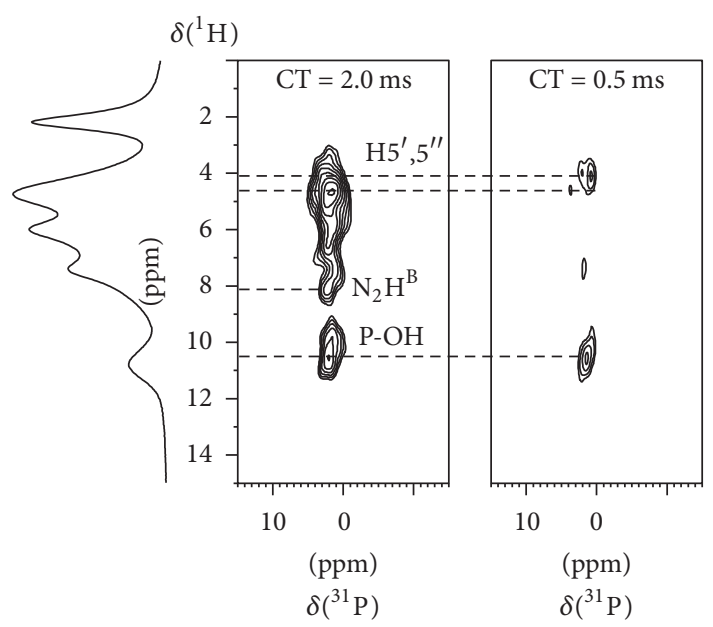

(a)

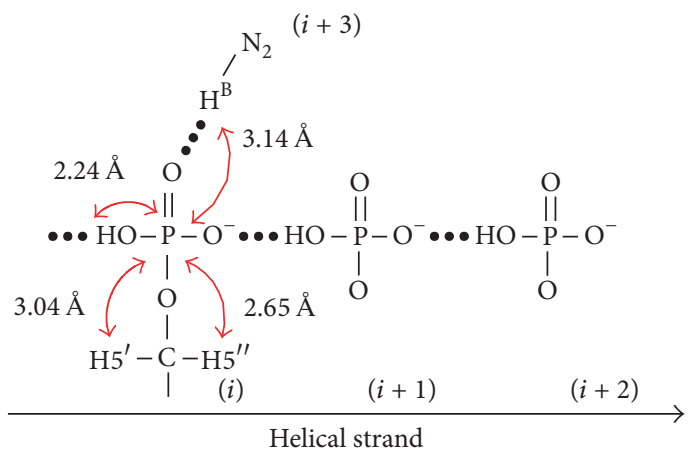

(b)

Figure 7: (a) 2D ${ }^{1} \mathrm{H} \rightarrow{ }^{31} \mathrm{P}$ HETCOR NMR spectra of the acidic $5^{\prime}$-GMP gel sample obtained at two different contact times (CT). (b) Predicted short contacts between the phosphate atom and several protons in the acidic $5^{\prime}$-GMP helical model.

${ }^{31} \mathrm{P}$ NMR spectrum of acidic $5^{\prime}$-GMP gel exhibits a sharp peak at $1.3 \mathrm{ppm}$ (vide infra), suggesting that all phosphate groups are equivalent. This is in contrast to the situation seen in the neutral $5^{\prime}$-GMP helix where two different phosphate groups are present with the ${ }^{31} \mathrm{P}$ chemical shifts being 3.7 and $5.2 \mathrm{ppm}$ [5]. Another important structural feature in the acidic $5^{\prime}$-GMP helix is the possible formation of a phosphatebase hydrogen bond, as first noted by Sasisekharan et al. [3]. In particular, the $i$ th phosphate group can be hydrogenbonded to the exocyclic amino group of the $(i+3)$ th guanine base (i.e., $\mathrm{N}_{2}-\mathrm{H}^{\mathrm{B}} \cdots \mathrm{O}=\mathrm{P}$ ) along the helical strand. In our model, the $\mathrm{N}_{2} \cdots \mathrm{O}(\mathrm{P})$ distance is ca. $2.82 \AA$.

To search for further spectroscopic evidence for the aforementioned two types of hydrogen bonding interactions involving the phosphate group (i.e., $\cdots \mathrm{HO}-\mathrm{P}_{i}-\mathrm{O}^{-} \cdots \mathrm{HO}-$ $\mathrm{P}_{i+1}-\mathrm{O}^{-} \cdots$ and $\mathrm{N}_{2}-\mathrm{H}^{\mathrm{B}} \cdots \mathrm{O}=\mathrm{P}$ ), we performed $2 \mathrm{D}{ }^{1} \mathrm{H} \rightarrow$ ${ }^{31} \mathrm{P}$ HETCOR experiments. As seen in Figure 7(a), at a short contact time of $0.5 \mathrm{~ms}$, two cross peaks were observed. The weaker cross peak with $\delta\left({ }^{1} \mathrm{H}\right)$ of $4.1 \mathrm{ppm}$ clearly arises from the short contacts between the phosphorus atom and $\mathrm{H} 5^{\prime}, 5^{\prime \prime}$ (2.65 and $3.04 \AA$ ), as illustrated in Figure 7(b). The stronger ${ }^{1} \mathrm{H}^{31} \mathrm{P}$ cross peak with $\delta\left({ }^{1} \mathrm{H}\right)$ of $10.5 \mathrm{ppm}$ is an interesting discovery, because we have already attributed, in the earlier discussion, $\mathrm{N}_{1} \mathrm{H}$ and $\mathrm{N}_{2} \mathrm{H}^{\mathrm{A}}$ to this overlapping signal. Now we see that a third signal, which displays the shortest contact with the $\mathrm{P}$ atom, also appears in this ${ }^{1} \mathrm{H}$ chemical shift region. This new signal must be due to the $\mathrm{P}-\mathrm{OH}$ group (the $\mathrm{H}$ $\mathrm{P}$ distance is ca. $2.24 \AA$ in our model); see Figure 7(b). As seen in Figure 7(a), a new cross peak corresponding to the $\mathrm{N}_{2} \mathrm{H}^{\mathrm{B}}$ group emerges at a longer contact time $(2 \mathrm{~ms})$. This is consistent with our model where the $\mathrm{P}$ atom is predicted to be $3.14 \AA$ away from $\mathrm{N}_{2} \mathrm{H}^{\mathrm{B}}$, due to the formation of a $\mathrm{N}_{2}-\mathrm{H}^{\mathrm{B}} \cdots \mathrm{O}=\mathrm{P}$ hydrogen bond. This hydrogen bond further explains why the ${ }^{1} \mathrm{H}$ chemical shift of $\mathrm{N}_{2}-\mathrm{H}^{\mathrm{B}}$, ca. $8 \mathrm{ppm}$, is considerably higher than those seen in the neutral $5^{\prime}$-GMP helix, 5.12 and $4.29 \mathrm{ppm}$ [5]. Close inspection of the acidic
$5^{\prime}$-GMP helix suggests that the formation of this strong $\mathrm{N}_{2}$ $\mathrm{H}^{\mathrm{B}} \cdots \mathrm{O}=\mathrm{P}$ hydrogen bond causes a tilting of the guanine base, thus making it more difficult to form a planar disclike $\mathrm{G}_{4}$. We postulate that the hydrogen bonding interactions between singly charged phosphate groups $\left(\cdots \mathrm{HO}-\mathrm{P}_{i}{ }^{-}\right.$ $\left.\mathrm{O}^{-} \cdots \mathrm{HO}-\mathrm{P}_{i+1}-\mathrm{O}^{-} \cdots\right)$ and between phosphate and guanine $\left(\mathrm{N}_{2}-\mathrm{H}^{\mathrm{B}} \cdots \mathrm{O}=\mathrm{P}\right)$ are the driving forces for the self-assembly of $5^{\prime}$-GMP into a continuous helix at $\mathrm{pH} 5$.

\section{Conclusion}

In this work, we have obtained new structural details about the helical structure formed by $5^{\prime}$-GMP at $\mathrm{pH} 5$. Contrary to the common assumption, we showed that this helix is composed of $5^{\prime}$-GMP molecules exclusively in $\mathrm{C} 3^{\prime}$-endo sugar pucker conformation and consequently is right-handed. In addition, we found that the central channel of the helix is free of $\mathrm{Na}^{+}$ions. In many aspects, this helix is drastically different from the one formed by $5^{\prime}$-GMP at $\mathrm{pH}$ 8. Remarkably, two different helices can form by the same molecule at just slightly different $\mathrm{pH}$ values. Of course, at $\mathrm{pH} 5$ and 8 , the charge state of the phosphate group would be different. The present study has provided another example where mononucleotides can self-associate into a helix in the absence of phosphodiester bonds. The solid-state NMR strategies demonstrated in this study can be applied to similar gels formed by other nucleosides and nucleotides.

\section{Conflicts of Interest}

The authors declare that there are no conflicts of interest regarding the publication of this paper.

\section{Acknowledgments}

This research was supported by the Natural Sciences and Engineering Research Council (NSERC) of Canada. The 
authors thank Andy Kalevar for his contributions at the early stage of this research.

\section{References}

[1] I. Bang, "Untersuchungen uber die guanylsäure," Biochemische Zeitschrift, vol. 26, pp. 293-311, 1910.

[2] M. Gellert, M. N. Lipsett, and D. R. Davies, "Helix formation by guanylic acid.," Proceedings of the National Acadamy of Sciences of the United States of America, vol. 48, no. 12, pp. 2013-2018, 1962.

[3] V. Sasisekharan, S. Zimmerman, and D. R. Davies, "The structure of helical $5^{\prime}$-guanosine monophosphate," Journal of Molecular Biology, vol. 92, no. 2, pp. 171-179, 1975.

[4] W. Saenger, Principles of Nucleic Acid Structure, Springer-Verlag, New York, 1984.

[5] G. Wu and I. C. M. Kwan, "Helical structure of disodium 5'guanosine monophosphate self-assembly in neutral solution," Journal of the American Chemical Society, vol. 131, no. 9, pp. 3180-3182, 2009.

[6] S. Elbers, W. Strojek, L. Koudelka, and H. Eckert, "Site connectivities in silver borophosphate glasses: New results from ${ }^{11} \mathrm{~B}^{31} \mathrm{P}$ and ${ }^{31} \mathrm{P}^{11} \mathrm{~B}$ rotational echo double resonance NMR spectroscopy," Solid State Nuclear Magnetic Resonance, vol. 27, no. 1-2, pp. 65-76, 2005.

[7] M. Feike, D. E. Demco, R. Graf, J. Gottwald, S. Hafner, and H. W. Spiess, "Broadband multiple-quantum NMR spectroscopy," Journal of Magnetic Resonance - Series A, vol. 122, no. 2, pp. 214221, 1996.

[8] T. Gullion and A. J. Vega, "Measuring heteronuclear dipolar couplings for $I=1 / 2, S>1 / 2$ spin pairs by REDOR and REAPDOR NMR," Progress in Nuclear Magnetic Resonance Spectroscopy, vol. 47, no. 3-4, pp. 123-136, 2005.

[9] C. L. Barnes and S. W. Hawkinson, "Structure of disodium guanosine 5-phosphate heptahydrate," Acta Crystallographica Section B: Structural Science, vol. 38, pp. 812-817, 1982.

[10] M. Ebrahimi, P. Rossi, C. Rogers, and G. S. Harbison, "Dependence of ${ }^{13} \mathrm{C}$ NMR chemical shifts on conformations of RNA nucleosides and nucleotides," Journal of Magnetic Resonance, vol. 150, no. 1, Article ID 92314, pp. 1-9, 2001.

[11] P. Rossi and G. S. Harbison, "Calculation of ${ }^{13} \mathrm{C}$ chemical shifts in RNA nucleosides: Structure- ${ }^{13} \mathrm{C}$ chemical shift relationships," Journal of Magnetic Resonance, vol. 151, no. 1, pp. 1-8, 2001.

[12] O. Ohlenschläger, S. Haumann, R. Ramachandran, and M. Görlach, "Conformational signatures of ${ }^{13} \mathrm{C}$ chemical shifts in RNA ribose," Journal of Biomolecular NMR, vol. 42, no. 2, pp. 139-142, 2008.

[13] H. Tajmir-Riahi, "Interaction of guanylic acid with the $\mathrm{Mg}(\mathrm{II})$, $\mathrm{Ca}(\mathrm{II}), \mathrm{Sr}(\mathrm{II})$, and $\mathrm{Ba}(\mathrm{II})$ ions in the crystalline solid and aqueous solution: Evidence for the ribose $\mathrm{C}^{\prime}$-endo/anti and C3'-endo/anti conformational changes," Biopolymers, vol. 31, no. 1, pp. 101-108, 1991.

[14] N. V. Hud and J. Plavec, "The role of cations in determining quadruplex structure and stability," in Quadruplex Nucleic Acids, S. Neidle and S. Balasubramanian, Eds., pp. 100-130, The Royal Society of Chemistry, Cambridge, UK, 2006.

[15] A. E. Engelhart, J. Plavec, and N. V. Hud, "Metal ion interactions with G-quadruplex structures," in Nucleic Acid-Metal Ion Interactions, N. V. Hud, Ed., pp. 118-153, RSC Publishing, London, UK, 2009.
[16] D. Rovnyak, M. Baldus, G. Wu, N. V. Hud, J. Feigon, and R. G. Griffin, "Localization of ${ }^{23} \mathrm{Na}^{+}$in a DNA quadruplex by high-field solid-state NMR," Journal of the American Chemical Society, vol. 122, no. 46, pp. 11423-11429, 2000.

[17] G. Wu and A. Wong, "Solid state NMR studies of alkali metal ions in nucleic acids and related systems," in NMR Spectroscopy of Biological Solids, A. Ramamoothy, Ed., pp. 317-344, CRC Press, Boca Raton, FL, USA, 2006.

[18] R. Ida and G. Wu, "Direct NMR detection of alkali metal ions bound to G-quadruplex DNA," Journal of the American Chemical Society, vol. 130, no. 11, pp. 3590-3602, 2008.

[19] A. Wong, Z. Yan, Y. Huang, and G. Wu, "A solid-state ${ }^{23} \mathrm{Na}$ NMR study of monovalent cation binding to double-stranded DNA at low relative humidity," Magnetic Resonance in Chemistry, vol. 46, no. 4, pp. 308-315, 2008.

[20] G. Wu and A. Wong, "Direct detection of the bound sodium ions in self-assembled $5^{\prime}$-GMP gels: A solid-state ${ }^{23} \mathrm{Na} \mathrm{NMR}$ approach," Chemical Communications, no. 24, pp. 2658-2659, 2001.

[21] A. Wong, J. C. Fettinger, S. L. Forman, J. T. Davis, and G. Wu, "The sodium ions inside a lipophilic G-quadruplex channel as probed by solid-state ${ }^{23} \mathrm{Na}$ NMR," Journal of the American Chemical Society, vol. 124, no. 5, pp. 742-743, 2002.

[22] A. Wong and G. Wu, "Selective Binding of Monovalent Cations to the Stacking G-Quartet Structure Formed by Guanosine 5 -Monophosphate: A Solid-State NMR Study," Journal of the American Chemical Society, vol. 125, no. 45, pp. 13895-13905, 2003.

[23] T. Giorgi, S. Lena, P. Mariani et al., "Supramolecular Helices via Self-Assembly of 8-Oxoguanosines," Journal of the American Chemical Society, vol. 125, no. 48, pp. 14741-14749, 2003.

[24] J. L. Sessler, M. Sathiosatham, K. Doerr, V. Lynch, and K. A. Abboud, "A G-quartet formed in the absence of a templating metal cation: A new 8-(N,N-dimethylaniline) guanosine derivative," Angewandte Chemie International Edition, vol. 39, no. 7, pp. 1300-1303, 2000.

[25] A. Neels, H. Stoeckli-Evans, J. Neels, A. Clearfield, and D. Poojary, "Ab Initio Structure Determination of Ammonium Hydrogen Alkyl Phosphates from X-ray Powder Diffraction Data," Acta Crystallographica Section B: Structural Science, vol. 54, no. 4, pp. 478-484, 1998. 

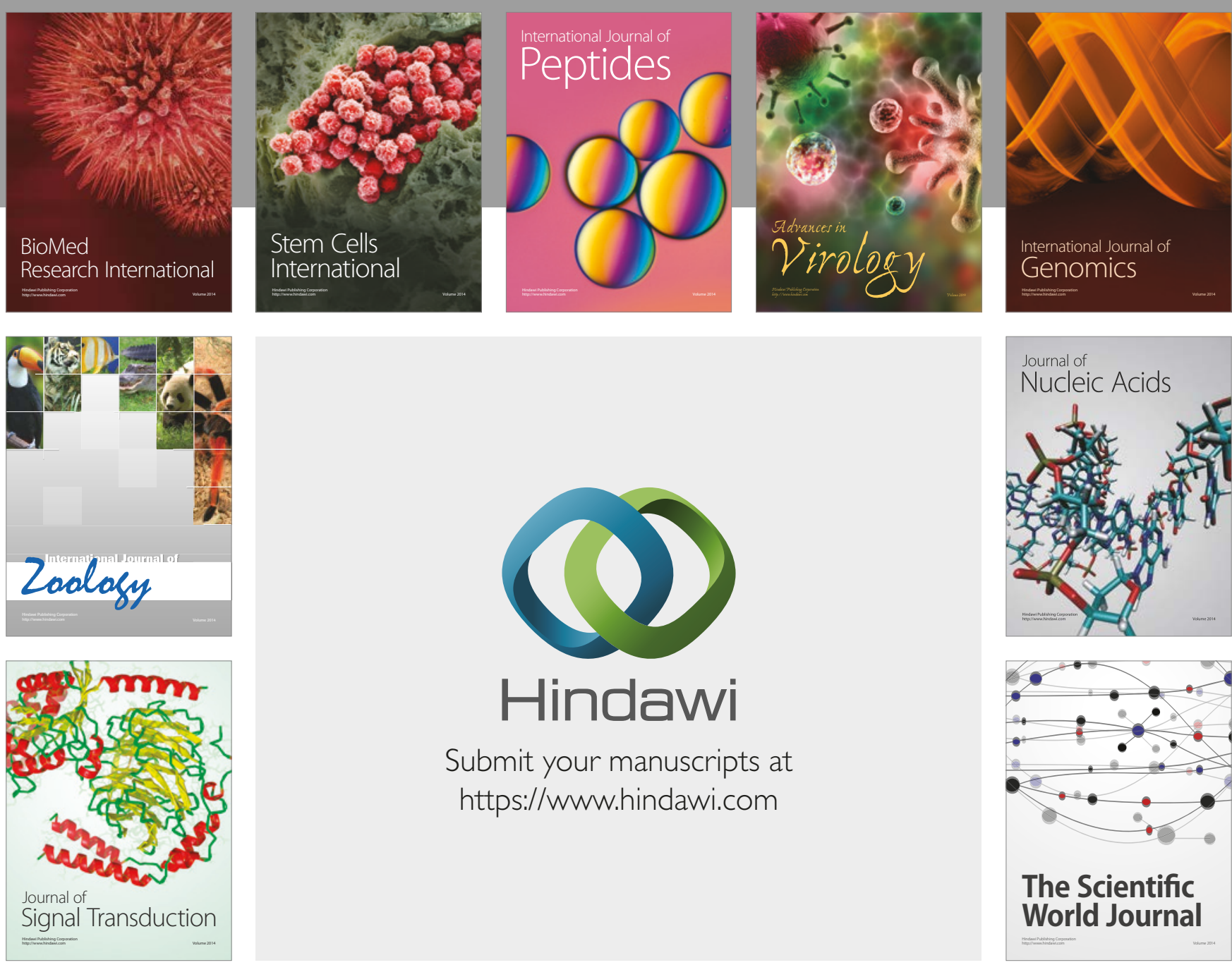

Submit your manuscripts at

https://www.hindawi.com
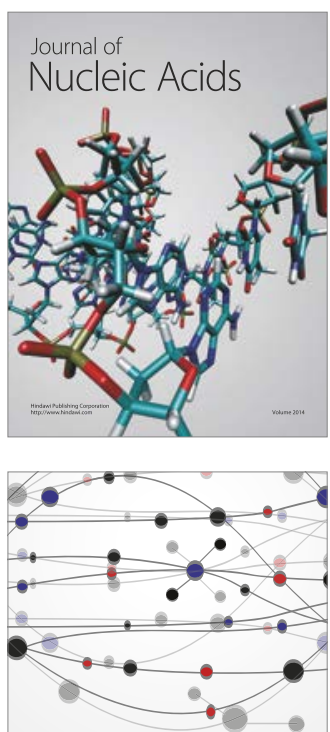

The Scientific World Journal

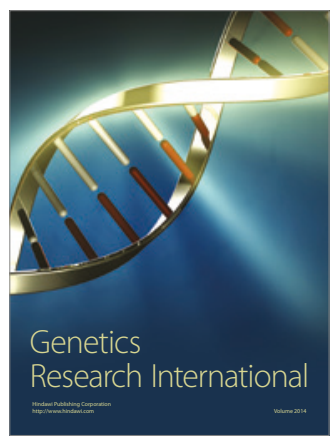

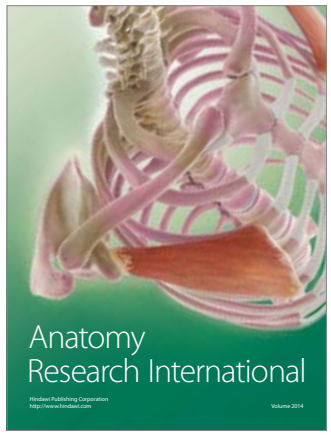

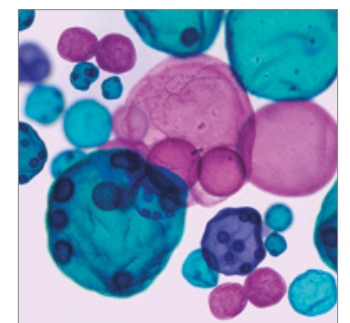

International Journal of Microbiology
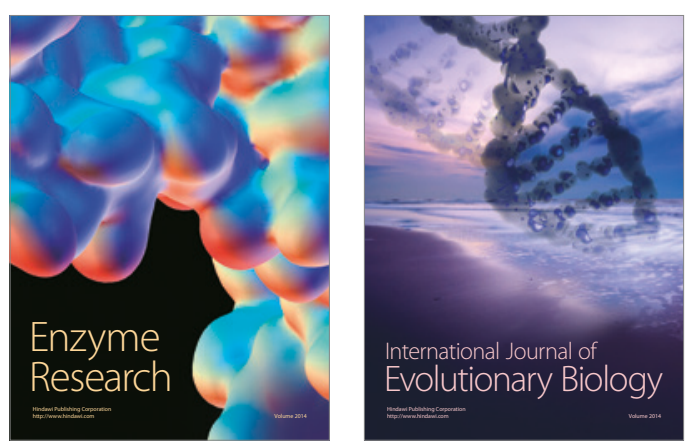
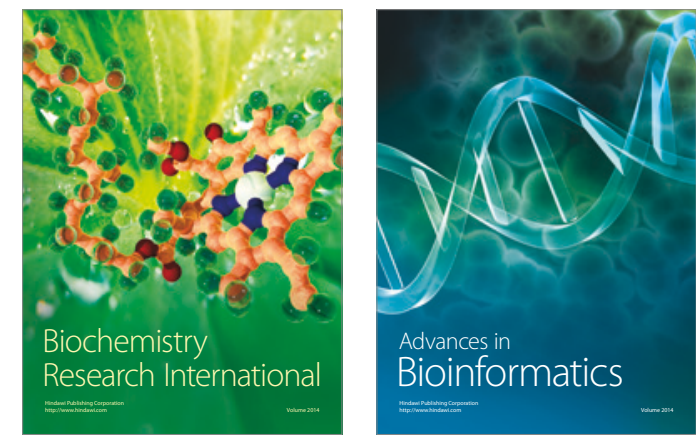

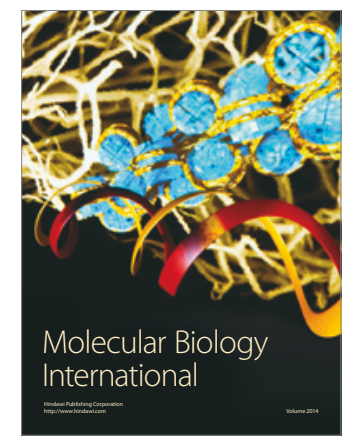

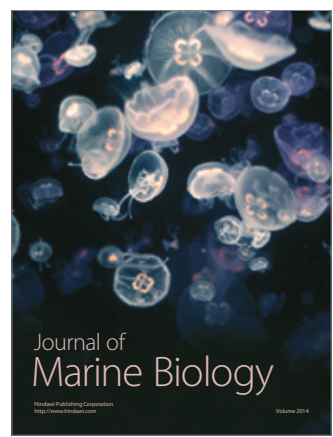

